\begin{tabular}{lllllll}
\hline REVISTA IBEROAMERICANA. & Vol. & LXII, Núm. & 174, & Enero-Marzo & $1996 ;$ & $13-25$
\end{tabular}

\title{
LA INTELECTUALIDAD NEGRA EN CUBA EN EL SIGLO XIX: EL CASO DE MANZANO'
}

\author{
POR \\ SONIA LABRADOR-RODRIGUEZ \\ University of Texas-Austin
}

Desde su origen, la autobiografia ${ }^{2}$ de Juan Francisco Manzano (1797-1854) ha sido motivo de diversas lecturas y ediciones. ${ }^{3}$ Por más de un siglo este texto ha sufrido cambios significativos en las versiones que existen de la obra, siendo cada una de estas ediciones producto del fin de cada editor que la ha interpretado. En cuanto a los estudios, la mayoría de ellos reconoce el valor testimonial de la autobiografia y tratan de disculpar faltas como problemas ortográficos, secuencia cronológica, estilo, etc., justificándolas con el argumento de la falta de educación que tuvo cuando esclavo (Centon IV:81; Schulman, "Introducción" 10, 48; Vitier 19-21). No ha sido sino hasta los últimos años que la lectura de la autobiografía ha rebasado el plano testimonial, gracias a los trabajos de Julio Ramos, William Luis, Sylvia Molloy, Antonio Vera León y Jill Netchinsky quienes han estudiado la complejidad del discurso literario de la autobiografia. Aunque estos análisis satisfacen distintos niveles de interpretación del testimonio de Manzano, creo, no obstante, se ha relegado a un segundo plano -sino ignorado-el nivel diríamos "teórico/crítico"de Manzano como un intelectual esclavo. La comodidad con que críticos y editores desde el siglo XIX se han acercado a la obra de Manzano en un intento por corregirla o re-escribirla provoca preguntarse si sería este el caso con cualquier otro texto de un escritor de calidad y fama incuestionable. ¿Tendrá que ver esta comodidad con el hecho de que Manzano haya sido un escritor esclavo? ¿Cómo se afecta la

\footnotetext{
' EI Instituto de Estudios Latinoamericanos de la Universidad de Texas-Austin apoyó parte de esta investigación con fondos que otorgó la Fundación Andrew W. Mellon al Instituto. Agradezco las sugerencias y comentarios de mis colegas Aline Helg y Naomi Lindstrom.

${ }^{2}$ Me refiero a "la autobiografia", porque Manzano nunca le puso título, siempre se refería a ella como "la historia de mi vida". En adelante las citas provienen de la edición de José Luciano Franco de 1937, admitiendo que esta edición tampoco está exenta de errores, la preferimos por acercarse más a la versión original.

${ }^{3}$ Escrita en 1835, las versiones de la autobiografia, hasta el momento conocidas son: la primera revisión, realizada a petición de Domingo del Monte por Anselmo Suárez y Romero; de ahí pasó la autobiografia a manos de Richard Madden quien la editó, tradujo al inglés y publicó en 1840. De la versión corregida por Suárez y Romero existen, hasta el momento, dos copias, una en la Biblioteca Nacional José Martí y la otra en la Universidad de Yale. Pero también consideramos ediciones las correcciones realizadas por Ivan Schulman y los comentarios de William Luis en "Autobiografia del esclavo ...", como explicaremos más adelante.
} 
definición de "intelectual" y su función social en el caso de un esclavo y más adelante exesclavo, en un régimen colonial esclavista?

La selección de Manzano como ejemplo no es arbitraria; más bien se debe a ser el autor esclavo más difundido en la literatura hispanoamericana. En su obra en prosa -incluyendo las cartas- así como en su obra poética y dramática, Manzano articula una denuncia de la esclavitud desde el punto de vista del creador/poeta esclavo. Esta articulación demuestra que su autobiografia no es un discurso espontáneo y arbitrario, sino que surge como resultado de la reflexión y la manipulación de los recursos literarios a su alcance. Tanto las ediciones que sufriera la obra, así como algunos de los acercamientos críticos sirven pare fundamentar mi propuesta de que Manzano y su trabajo literario han sido subordinados en una relación de poder con sus patrocinadores y editores y hasta con algunos de sus lectores más recientes.

La autobiografia de Juan Francisco Manzano, además de ser una denuncia del régimen esclavista, es una manifestación del deseo de libertad de un individuo y el triunfo de su lucha por expresar artísticamente su subjetividad. ${ }^{4}$ La autobiografia es producto de una lucha de poder entre el esclavo y el amo; es el resultado de una negociación entre la sacarocracia liberal cubana - representada en la figura paternalista de Domingo del Monte, patrocinador de la intelectualidad cubana- y el esclavo que busca su libertad y seguridad. Lúcidamente, Manzano se refiere a la "historia de su vida" como la lucha de un "ser muerto", como queriéndonos decir que es un ser desprovisto de todo discurso cultural, histórico y social. Su lucha pues, es una por la búsqueda de un modo de expresión propio. ${ }^{5}$

Desde 1821 Manzano se había unido a la reducida lista de intelectuales de color que había logrado publicar en las primeras décadas del siglo, primero por la publicación de Poesías líricas (1821) y más adelante, sus Flores pasageras (1830). En 1834 aparecieron los Romances cubanos, que consistían en seis poemas publicados en el periódico matancero El pasatiempo (Friol 91-149). ${ }^{6}$ En una de las veladas literarias de del Monte (1836) se leyó el poema "Mis treinta años", que conmovió a los presentes y que junto a lo ya publicado contribuyó a la fama del poeta-esclavo, y eventualmente a su libertad. De manera que cuando del Monte conoció a Manzano, éste ya era relativamente famoso. En estas circunstancias, no fue casual que del Monte pensara en él como la fuente primaria de un texto sobre la esclavitud. Años más tarde, su testimonio pasó a formar parte del álbum que preparó del Monte al cónsul inglés Richard R. Madden.

Además de las cualidades literarias y de la fama de Manzano, que para la elite cubana eran insospechadas en un esclavo, creemos que hay otro factor que pudo haber contribuido a que

\footnotetext{
${ }^{4}$ Sobre la construcción del sujeto en el texto de Manzano, ver el artículo de Julio Ramos, "Cuerpo, lengua, subjetividad".

${ }^{5}$ La interpretación de la autobiografia que hace Sylvia Molloy se basa precisamente en que la original idad de la obra de Manzano radica en su prosa, pues contrario a su obra poética, para su narrativa no existían modelos a imitar.

${ }^{6}$ La producción poética de Manzano no se limita a lo publicado en las diversas ediciones conocidas. Tanto en los manuscritos de la Biblioteca Nacional de Madrid como en el de Yale se encuentran poemas inéditos. En el artículo citado en este trabajo, Adriana Lewis Galanes hace un análisis del carácter denunciatorio del régimen esclavista y la afirmación de la identidad racial en la obra de Manzano a partir de los poemas que descubrió en la Biblioteca Nacional de Madrid. De los que cita, me parece que el más interesante sería "La visión del poeta. Compuesto en un ingenio de fabricar azúcar".
} 
del Monte pensara en Manzano para su encargo. En carta a del Monte(16 oct., 1834), Manzano le confiesa que anteriormente le había escrito cinco cartas en que le hablaba de varios asuntos:

... esperanzas y lamentasiones unas, motivos $p^{\prime} \cdot q^{\circ}$. me iva resfriandoen el trato de las musas otra; como se me ofreció la coyuntura de ganar mi livertad, $y$ como se desvanesió todo, en otra, y deste modo una relasion de como vivo desengañado de algunas felises ideas $q^{\mathrm{e}}$. me isieron respirar tranquilo algunos dias (Franco 78, énfasis mío).

Según el propio Manzano cuenta, por miedo a irritar a del Monte con sus quejas nunca las envió, pero estas cartas sugieren una especie de relato autobiográfico que presentan potencialmente dos claves que yo interpreto como principio estructurador del relato que finalmente compuso: las dificultades que implica su búsqueda de la libertad y más importante aún, el deseo de articular su situación como intelectual esclavo - "motivos p $\mathrm{p}^{\mathrm{r}} \mathrm{q}^{\mathrm{o}}$. me iva resfriando en el trato de las musas otra"-(78). La primera narración antiesclavista fue escrita por un esclavo, que siguió instrucciones de cómo debía ser el retrato que pintaba. Sin embargo ese retrato, a pesar del trabajo editorial de varios letrados, resultó ser mucho más de lo que se le encomendó a Manzano. El acto de escritura representa para Manzano un acto de libertad y al mismo tiempo de subyugación, de reivindicación pero también de humillación. Al escribir Manzano sabe que no puede decir todo lo que siente y sabe, que su escritura le permite ejercer la libertad de pensar y articular sus ideas, siempre y cuando se atenga al código que rige su vida como esclavo. Pero también plantea un problema; no sabe comportarse como escritor-esclavo porque para esta situación no existe código alguno. Manzano viene a convertirse en su propio marco de referenciay al relacionarse con los intelectuales blancos va tanteando cuidadosamente sus reacciones. Manzano entra en una relación de poder excepcional con sus lectores. El hecho de que sea un relato autobiográfico no implica necesariamente que sea un relato espontáneo o ingenuo, como veremos. Siendo el narrador que controla la historia, usa diversas estrategias para lograr sus fines como autor, pero también se siente intimidado por su lector. Por un lado, sabe que los lectores pertenecen a la misma clase de los amos que lo han castigado y no tiene certeza de cómo reaccionarán a sus acusaciones. Por el otro, al escribir sobre las vejaciones que ha sufrido se reivindica al denunciarlas, pero se humilla al admitirlas, pues teme que para el rector, su condición de esclavo socave su dignidad como ser humano y como poeta. ${ }^{7}$ En la misma carta del 25 de junio Manzano confiesa que ha estado a punto de dejar de escribir su historia al darse cuenta de la contradicción en la que escribe:

he estado mas de cuatro ocasiones $\mathrm{p}^{\mathrm{r}}$. no seguirla, un cuadro de tantas calamidades, no parese sino un abultado protocolo de embusterias, y mas desde tan tierna edad los crueles azotes me asian conoser mi umilde condision; me abochorna el contarlo, y no se como demostrar los hechos dejando la parte mas terrible en el tintero, y ojala tubiera otros hechos con $\mathrm{q}^{\mathrm{e}}$. llenar la historia de mi vida sin recordar el esesivo rigor con $\mathrm{q}^{\mathrm{e}}$. me ha tratado mi antigua ama (8384).

\footnotetext{
${ }^{7}$ Friol, Netchinsky, De Costa-Willis y Molloy hacen una lectura de la autobiografia de Manzano como testimonio de una doble vida, como poeta y como esclavo.
} 
Para interpretar la obra y vida de Manzano como ejemplo del intelectual negro en la Cuba colonial esclavista, es necesario recordar que la cultura del cubano de color no proviene enteramente del mundo letrado, sino también del mundo oral. El caso de Manzano pertenece a la serie de ejemplos en la historia que revelan la compleja relación entre la formas de "alta" y "baja" cultura. ${ }^{8}$ El hecho de que Manzano sea autodidacta y que utilice el encargo que le han hecho para hablar de lo que no le han pedido - su reflexión sobre la represión del artista de color - lo hacen susceptible de ser admirado y temido. Por esta razón nos aventuramos a conjeturar que la edición que ha sufrido su texto no ha sido únicamente producto de la agenda antiesclavista de los intelectuales de la época, (Luis, "Autobiografia") sino también del temor a que se produjera un saber independiente, fuera del control de la elite criolla.

Manzano acepta la propuesta de escribir el testimonio de su vida como esclavo porque ve en ello no sólo la posibilidad de conseguir la libertad, sino también la oportunidad de expresar lo que sabey siente. De esta maneraabre la vía de comunicación que le ha sido consistentemente reprimida toda su vida. Manzano no resiste la tentación de contar, ${ }^{9}$ de establecer un diálogo con los que representan el saber para él —el amo, los otros intelectuales - aunque la respuesta tenga consecuencias terribles. Después de tantos años buscando un medio de expresión, no puede dejar pasar la oportunidad de dialogar con un público culto.

Manzano como narrador, centrará su crítica en tres estrategias principales. Primero, la narración rechaza un orden cronológico y privilegia uno de acontecimientos. Concretamente, Manzano se basa en los castigos que recibió para demostrar la crueldad y arbitrariedad del sistema esclavista. Segundo, Manzano elabora un sujeto en la narración que se distancia del esclavo y se acerca más a un ser humano sensible e inteligente, estrategia que, como veremos, permite que el lector pueda identificarse con él. Finalmente, como resultado de la imagen que crea del protagonista, se define como intelectual y narra el proceso sistemático por el que fue reprimido, castigado y torturado.

Una de las preguntas necesarias al acercarse a la estructura y orden seleccionados por el narrador es, cuáles son las consecuencias de su opción organizativa, que no fue entendida por sus lectores y correctores. Manzano comienza la historia de su vida con su nacimiento y niñez. Más que su origen, quiere resaltar el hecho de que era bien tratado y feliz. Sin embargo, a esta parte de su vida le dedica unos pocos párrafos y más adelante señala que privilegiará en la narración, la "verdadera historia de su vida" (Franco 38), es decir, la parte que él considera más significativa. Manzano advierte al lector que en su recuento "no ai epocas fijas" (38). Está consciente de que su relato carece de una secuencia cronológica, pues insiste que eso no es lo

\footnotetext{
${ }^{8}$ El caso de Manzano es muy similar al del Molinero Menoccio que Carlo Ginzburg estudia en su libro El queso y los gusanos. Como Manzano, Menoccio fue autodidacta y fue procesado por la Inquisición por hereje. Más que el cuestionamiento de un orden cosmogónico, su culpa era ser una amenaza para la autoridad por el carácter independiente de su saber. Ginzburg analiza las implicaciones del estudio del sujeto histórico para entender el carácter paradójico de la dominación. Ginzburg se basa en Bajtín para plantear que las formas discursivas dominantes no son las únicas que hay que analizar porque lo que ocurre en relación a la producción intelectual no es el producto de la imposición de formas "altas" de cultura sobre formas "bajas", sino el producto de la circulación de las mismas, lo que hace a este tipo de personas amenazante.

${ }^{9}$ Dice Manzano: "era tal el flujo de ablar $q^{e}$. tenia $q^{e}$. $p^{r}$. ablar ablaba con la mesa con el cuadro con la pared \&" (41).
} 
importante, porque su criterio es otro: "Asi saltando $\mathrm{p}^{\mathrm{r}}$. ensima de barias epocas dejando atras una multitud de lanses dolorosos me señire únicamente a los mas esenciales como fuente 0 manantial de otras mil visisitudes" (49), y más adelante insiste: "asi determino descrivir los susesos mas notables $q^{e}$. me han acarreado una opinion tan terrible como nosiva" (51).

Esta lúcida conciencia de la estructura y orden narrativo demuestra que aunque autobiográfica, la narración de Manzano no es necesariamente un relato espontáneo y cándido, como han querido ver algunos críticos (Bueno 64). Creer esto implicaría una subestimación de su capacidad como narrador. Manzano cuenta los hechos de una manera selectiva y de acuerdo a lo que pretende demostrar. Hablando sobre el género autobiográfico, James Olney dice que aunque la autobiografía es un ejercicio de la memoria, tanto la selección de los hechos como la manera en que se presentan, es producto de la capacidad imaginativa del narrador para crear un significado particular. Pero Olney señala que en la autobiografía escrita por esclavos no es posible reordenar los eventos de acuerdo a los propósitos del narrador para crear además de una "dimensión episódica", "una dimensión configurativa". En su presión por decir la verdad sin duda y claramente, en la narración de los ex-esclavos prevalecía un orden episódico $\mathrm{y}$, por lo tanto, no existía un distanciamiento que le permitiera al narrador reflexionar sobre la memoria y el acto de recordar ("I was" 149-151). Sin embargo, Manzano es una notable excepción a lo que propone Olney porque en su narración sí hay una selección y ordenación de eventos que subvierte el orden cronológico.

Una lectura comparada del texto original y el corregido por Anselmo Suárez y Romero revela que el orden no-cronológico fue rechazado por dicho corrector. Por ejemplo, la narración de los castigos que sufre muestra una diferencia entre el texto original y la versión corregida por Suárez y Romero. Suárez alteró el orden tal vez buscando en el texto claves para encontrar cierta coherencia cronológica. Pero el propio Manzano admite que hay un problema en el orden de los sucesos porque aclara en una nota al calce el orden correcto referente a un episodio en particular (59). Suárez se deja guiar por esta nota para su corrección, omitiéndola luego en su edición. Ésta no es la única corrección que hace Suárez; la más importante para este trabajo es una referente a la producción literaria de Manzano. Refiriéndose al proceso de su educación, Manzano explica la importancia de la poesía en su vida: "empese yo también a darme estudios, la poesia en todos los tramites de mi vida me suministraba versos analogos a mi situasion ya prozpera ya adversa", (54, énfasis mío). Suárez omite la sección subrayada. Esta importante omisión evidencia el choque de valores entre Manzano y los editores representados por Suárez. En Suárez se hace patente el deseo de dar coherencia a la obra; en su corrección hay también una manifestación paternalista y condescendiente hacia el pensamiento y trabajo intelectual de Manzano, pues Suárez no reconoce la gravedad de las correcciones que ejecuta, a juzgar por la declaración que acompañó los manuscritos en 1859, cuando se los cede a Vidal Morales:

Declaro solemnemente que cuando corregí los originales de Manzano, casi no hice otra cosa que enmendar las faltas ortográficas, respetando los vocablos y las construcciones usadas por el autor; y ahora confieso que si esta copia se limara un poco más, resultarían unas páginas más dignas de la estampa sin que por ello perdiesen el candor y la verdad con que fueron escritas (Friol 231). 
Varios estudios han empezado a denunciar el caracter paternalista de las ediciones/ lecturas de la autobiografía. William Luis hace una lectura de las versiones de la autobiografia como textos diferentes, de acuerdo a los propósitos de los correctores-editores que la han intervenido. Concluye en Literary Bondage que el trabajo editorial de estos intelectuales representa otra forma de subyugación para Manzano. Luis centra su lectura en las correcciones que hizo Richard Madden a la obra y otro de sus trabajos lo dedica a las correcciones hechas por Suárez ("Autobiografia"). Jill Netchinsky demuestra cómo la edición de Schulman indica una actitud condescendiente hacia el trabajo de Manzano pues inserta la autobiografia como una parte más del trabajo crítico de Schulman. Finalmente, Sylvia Molloy destaca la manera en que Madden convierte el texto de Manzano en un texto genérico, representativo de la esclavitud. Madden lo despoja de su autor (es anónimo), lo edita, y, como Schulman, lo incorpora dentro de otros textos escritos por él. Luis acierta al señalar la relación de poder entre los editoresy correctores y Manzano: "The editors, as surely as slave masters, continue to mold and control Manzano's life ... Like del Monte, who wanted to help Manzano gain his freedom, Franco, Suárez y Romero, Schulman, Calcagno and Madden in their own way assisted Manzano with his manuscript. But in so doing they have also altered it" (Literary 99). Pero el propio Luis intenta una reconstrucción del texto como lector-corrector del texto de Manzano: "Si nosotros, como lectores, reconstruyéramos la vida de Manzano no como él la narra ni como Azcarate nos la presenta, sino en la forma en que el esclavo la vivió, esta otra autobiografia tendría un resultado diferente" ("Autobiografia" 266). Luis insiste en que la reconstrucción por parte del lector contemporáneo, es la que más se acerca "a la vida real del esclavo", y concluye que la versión de Suárez y Romero es "la más convincente protesta antiesclavista" (267). Lo que Luis define como una "tercera versión" que permite explicar detalles de la vida de Manzano plantea dos consecuencias. Primero, cuestiona el nivel literario del texto, pues es difícil contrastar la veracidad de los hechos "reales" con el texto literario de Manzano. Segundo, este tipo de lectura cuestiona el intento de Manzano de expresarse y organizar su discurso, no sólo como un esclavo, sino también como un escritor, e inclusive, despoja el texto original de su principal cualidad, que es la denuncia del régimen esclavista desde el punto de vista de un poeta esclavo, pues es en la versión de Suárez que Luis encuentra la denuncia antiesclavista más convincente.

La corrección de textos por otros escritores era una práctica generalizada a principios del siglo XIX, por lo que Manzano no era un caso excepcional. Suárez corrige a Manzano; a su vez, la novela de Suárez es corregida por González del Valle, todos representando a del Monte e informándole del progreso de sus protegidos. De hecho, muchos de los poemas escritos por Manzano fueron corregidos por del Monte, a juzgar por las cartas del poeta a su patrocinador. La corrección de estas obras esta íntimamente vinculada al interés y la posibilidad de publicar. Los testimonios recogidos en colecciones epistolares como el Centón epistolario de Del Monte y La vida literaria en Cuba de José Zacarías González del Valle, ofrecen repetidas muestras de los intentos de varios escritores por satisfacer las exigencias de del Monte y conseguir su aprobación para lograr publicar sus trabajos. Corregir era una forma más de ejercer el poder en un lugar en que el sistema colonial dejaba poco espacio pare ejecutarlo. Sin embargo, lo que hace el caso de Manzano excepcional -aparte de que las correcciones no fueron resultado del diálogo con el autor-es que el deseo de intervención en la obra aún continúa. Resulta muy sugerente el contenido de lo que Suárez y Madden omiten: las críticas 
del poeta a su trabajo intelectual. Pero no era Manzano y su discurso teórico lo que interesaba a los intelectuales, sino su testimonio, y esto no era una excepción en el desarrollo del movimiento antiesclavista en el Nuevo Mundo: "The lives in the narratives are never, or almost never, there for themselves and for their own intrinsic, unique interest but nearly always in their capacity as illustrations of what slavery is really like. Thus in one sense the narrative lives of the ex-slaves were as much possessed and used by the abolitionists as their actual lives had been by slaveholders" (Olney, "I was born" 154).

Bajo la promesa implícita de conseguir su manumisión a cambio de la historia de su vida, Manzano se somete a del Monte en una relación de sujeción que, según explica Patterson, es otra manifestación de la esclavitud. ${ }^{10}$ La promesa de manumisión se convierte en un incentivo, que, como la técnica del buen trato que promueven los hacendados liberales, pretende lograr una conducta deseada en el esclavo: la efectiva realización de una tarea ltexto. Por estar escrita sobre la base de la recompensa y por su deseo de expresarse artísticamente, la autobiografía de Manzano se desarrolla en una tensión entre el sometimiento y la rebelión. Manzano quiere trascender la tarea impuesta y dejar impresa en el lector su imagen como poeta. Quiere condenar la esclavitud buscando la libertad y necesita convencer al lector de que la merece. Para lograrlo, ¿cómo puede Manzano llegar a causar cierta simpatía en el lector para que se identifique con él siendo un esclavo? Manzano opta por construir una imagen de él común a los valores que él le atribuye a su lector. " Debe evitar su identificación con el negro y el esclavo, y construir un sujeto de la narración en sustitución del esclavo negro, con el cual pueda sentirse identificado su lector. ${ }^{12}$ En varias ocasiones Manzano insiste en que tanto sus amos como su padre le prohibían que se asociara con otros negros $(37,68)$. En cuanto al empleo de la palabra esclavo para referirse a su situación, no aparece sino haste el final de la obra. ${ }^{13}$

El que Manzano evite asociarse con negrosy esclavos en la autobiografia ha sido producto de interpretaciones del texto como una justificación del deseo de Manzano por acercarse al mundo del blanco. Vista como una estrategia discursiva, puede interpretarse de una manera diferente. El narrador substituye la imagen del negro esclavo por un ser inteligente y sensible que es víctima de la arbitrariedad y del destino. Una especie de fatalidad que trasciende la estética romántica, persiste en toda la obra de Manzano. Es lo que caracteriza a los protagonistas de Zafira (30), o poemas como "Oda: En la Noche de mi Cumple-Años" -

\footnotetext{
10 “... while we normally think of manumission as being the result of the negation of slavery, it is also true that manumission, by providing one of the major incentives for slaves, reinforced the master-slave relationship" (341).

"En "The Slave Narrative as Rhetorical Art", Doyle utiliza la teoría del "reader response" para analizar cómo la narrativa escrita por esclavos busca en el lector una identificación con el personaje-narrador. En el ejemplo específico que estudia, el narrador (85-89) se identifica con personajes bíblicos e históricos que han sufrido el exilio.

${ }^{12}$ Según el análisis hecho por Netchinsky, Manzano busca la simpatía del lector al establecer un vínculo con él a través del código "quasi Romantic" y al aludir al carácter noble de los amos; facilitando así que el lector se identifique doblemente con la lectura, como buen amo y como hombre ilustrado. Ver en especial, las páginas 41,54 y 61 de su tesis doctoral.

${ }_{13}$ La palabra esclavo aparece anteriormente al momento en que nos referimos una sola vez, cuando Manzano, utiliza la negación de su condición al referirse al trato que le daba don Nicolás dice que lo quería, "no como a esclavo sino como a hijo" (56).
} 
atribuido a Manzano- así como el dejo quejumbroso de sus cartas a del Monte. Todos estos textos demuestran una coherencia con el sujeto de la autobiografia. Además de presentarse como un ser sensible castigado por las "burlas" de la "fortuna" ( 16 oct., 1834, Franco 79), Manzano hace innumerables esfuerzos por demostrar su carácter especial: el trato preferencial de su primera ama, y particularmente su educación. Esta tercera y última estrategia es para mí la más importante, pues a través de ella pretende convencer al lector de que puede identificarse con el sujeto de la narración y además presenta la denuncia del régimen esclavista desde otro punto de vista, del poeta reprimido.

Manzano elude en varias ocasiones a sus conocimientos, que empezaron de niño: " $p r$. demasiado vivo mas $q^{e}$. todos, se me enbió a la escuela en casa de mi madrina" (34). Nos cuenta cómo aprendió sermones, loas y entremeses y las oportunidades de asistir a óperas francesas (35). En su intento por mostrar su esfuerzo por educarse y convertirse en "un hombre de bien" Manzano, además de revelar el proceso de educación que lo distingue de los otros esclavos, (16 oct., 1834, Franco 79), revela su conciencia de la represión de que fue objeto. ${ }^{14}$ Hay tres instancias en la narración en que Manzano cuenta de una manera sistemática sus intentos por aprender a comunicarse a través de la expresión artística y es reprimido: cuando Manzano aprende a leer, y como consecuencia de lo que escucha y lee, compone poesías y cuentos en su memoria, cuando aprende a dibujar y cuando aprende a escribir.

Sobre el primer intento, Manzano recuerda cómo a pesar de que sus padrinos no querían que aprendiese a escribir, él le dictaba sus composiciones "a una joven morena llamada Serafina" (38). Con frecuencia Manzano hacía cuentos a los niños, "y le cantaba cuentos de encantamientos $q^{e}$. yo componia de memorias en el resto de el dia con su cantarsito todo conserniente a la aflictiva imagen de mi corazón" (41). Una vez en que lo sorprendió la marquesa de Justiz, su ama, lo castigó poniéndole "una grande mordaza" y con "recta proivision" para que nadie conversara con él (41). Al aprender a dibujar recibió el elogio del maestro de los amos, Mr. Godfria (40). Manzano recuerda y describe dos de los dibujos, el primero, "una muger desolada $q^{e}$. corria con el pelo suelto ensortijado y batido $p r$. el viento los ojos saltones y llorosos" (40), el segundo, "una bruja hechandole una alluda a un diablo aquel tenia el semblante aflijido y la bruja risueño" (42). Su padre, al sorprenderlo dibujando la bruja y el diablo, le "proibió" pintar y rompiendo el dibujo tiró al río los materiales de Manzano (42). El tercer intento de Manzano consistió en aprender a escribir. Manzano dice que se fue "identificando de tal modo con" las costumbres de su amo, don Nicolás de Cárdenas, " $q$ e. empese yo también a darme estudios, la poesía en todos los tramites de mi vida me suministraba versos analogos a mi situasion ya prospera ya adversa" y aprende a escribir, pero su amo lo reprende, "imponiendome dejase aquel entretenimiento como nada correspondiente a mi clase"; no obstante, empezó a escribir versos, y "el Sor. Dr. coronado fue el primero qe. pronostico $q^{e}$. yo seria poeta" (57).

Los tres incidentes muestran la misma estructura narrativa. Hay un agente facilitador: Serafina - y los chicos que lo animan a relatar historias-; Mr. Godfria y el Dr. Coronado. Todos constituyen un estímulo para que continúe su creación o aprendizaje. Además, hay un

\footnotetext{
${ }^{14}$ Olney señala que utilizar la autobiografia para relatar la lucha por la alfabetización y el intento de reprimirla por parte de los amos, fue una constante en la narrativa escrita por ex-esclavos en Estados Unidos.
} 
agente represor: los padrinos/la Marquesa de Justiz, el padre y don Nicolás. Tercero, en cada uno de los episodios repite o utiliza distintas formas del verbo prohibir: "hizo recta proivision", "me proibio" (dos veces). Finalmente, el contenido de cada creación representa el sentir de Manzano, por lo general, corresponde a la "aflictiva imagen" de su corazón: los cuentos y versos son tristes, la mujer está "desolada", "el diablo afligido" y la poesía refleja hechos prósperos y "adversos" de su vida, que mantienen una coherencia con el contenido de la obra de Manzano. La sistematización de la estructura y el contenido de los episodios nos revela un comentario articulado sobre el proceso de creación y represión. ${ }^{15}$

Manzano está consciente y expresa su lucha contra la prohibición de aprender. $\mathrm{Su}$ vocación es más fuerte que el temor a ser castigado, y es tal su empeño que se asigna lecciones $(57,66)$, le roba horas al sueño para practicar su escritura (57) o aprovecha cualquier momento que tiene para copiar a escondidas trozos de poesías que oía recitar en las veladas de su ama (66). Como ha señalado Molloy, Manzano sobrevive fisica e intelectualmente de las sobras que roba de la mesa del amo (49). Aprender se convierte en la única vía de rebelión contra el amo. Al violar la prohibición, trata de acercarse al mundo del amo, que le es constantemente vedado, como afirma Vera León: "La esclavitud silencia, por lo que el acto de rebeldía es hablar, escribir, publicar, de manera que la voz de Manzano niega el poder del amo ... La historia de la escritura de Manzano es la del encuentro a escondidas con la letra: una escritura que surge de la rapiña y la voracidad satisfechas a espaldas del amo" (20).

Al alfabetizarse, Manzano rompe con el monopolio del saber del hombre libre, se acerca a él en cuanto es capaz de articular sus ideas y de definirse como no-esclavo. Al relatar su experiencia con la palabra escrita, Manzano cobra consciencia de su identidad como poeta, como hombre de letras. Aprovecha varias ocasiones en su relato para hablar de algo que no le han pedido, el origen y crítica de su trabajo intelectual. Reconoce en su condición de esclavo la fuente de su poesía: "la poesia en todos los tramites de mi vida me suministraba versos analogos a mi situasion ya prozpera ya adversa" (57). En otras ocasiones, comenta la fuente de la poesía y explica por qué la suya carecía de originalidad, como si se anticipara a futuros críticos (Kutzinski 82). Señala el narrador: "la poesia quiere un objeto a quien dedicarse, el amor regularmente nos inspira yo era demasiado ignosente y todavia no amaba de consiguiente mis composiciones eran frias imitaciones" (66). Estos ejemplos revelan, que desea e intenta hacer una reflexión crítica en el contexto de su condición: la esclavitud le inspira a la creación artística, pero al mismo tiempo limita sus modos de expresión. El 11 de diciembre de 1834 Manzano le explica a del Monte: "mi esclavitud no ha sido mas $q^{\circ}$. un conjunto de calamidades y desabrimientos, tales son los versos $q^{e}$. me inspiraba mis triste situasion" (81). Con este gesto, Manzano se convierte en creador, crítico y teórico de su obra. Explica la relación entre su poesía y su vida. Al comentar el carácter de su producción artística, su narración se convierte en un metadiscurso, pues comenta lo que escribe simultáneamente al momento de su escritura: vida, versos y autobiografía quedan entrelazadas. Pero también cumple la función de teórico pues

${ }^{15}$ En este contexto nos parece significativo que Schulman encuentre que Manzano privilegia las experiencias como esclavo y subordine sus experiencias y reflexiones como poeta. En su introducción, se pregunta Schulman: "Y, por qué, siendo ésta la autobiografia de un esclavo-poeta, no trata, sino en forma breve, su vida artística, prefiriendo el esclavo pintarnos aquella 'suceción de penitencia, encierro, azotes y aflicciones' que fue su sufrimiento diario" (22). 
tanto la autobiografia como las cartas que escribe a Manzano explican su poética: es decir, la relación entre la fuente de inspiración y las experiencias vitales.

Escribir la historia de su vida a petición de un personaje ilustrado le da a Manzano la oportunidad de manifestar su saber, de entrar al mundo del letrado y ser avalado por el reconocimiento de otros intelectuales. Poder articular su discurso según su orden de valores no sólo implica, como señalaba Vera León, un acto de subversión contra el amo que lo reprime, sino también contra los otros amos, el que le pide la autobiografía a cambio de su libertad, el que lo corrige. A pesar de la situación que lo limita al escribir (la doble censura impuesta por la Metrópoli a los cubanos y de los intelectuales cubanos al esclavo) Manzano crea estrategias alternativas para complacer y al mismo tiempo subvertir el orden del discurso antiesclavista, que según Olney caracteriza los relatos escritos por esclavos:

It is explicitly an act of assertion and aggression against the slaveholders who tried to prevent the slaves ever learning to read and write; and it is implicitly an act of assertion and aggression against abolitionists who were too often inclined to confuse sponsorship with authorship and to take possession of "their" ex-slaves in a manner not altogether unlike the original possession by slaveholders ("The Founding" 5).

Se ha señalado con decepción que Manzano se silenció como poeta al ser manumitido. ${ }^{16}$ Schulman atribuye a su ambigüedad racial y social "a source of frustration, confusion and premature silence in his life as a writer"("Juan Francisco"31). Para este crítico, el móvil central de la autobiografía era alcanzar la libertad, y al perder su móvil, Manzano se vio atrapado en las contradicciones de sus deseos por "incorporarse a la sociedad blanca", es decir, blanquearse al menos culturalmente ("Introducción" 20), abandonando su origen racial y cultural: "En este sentido, en la obra de Manzano hay un venero escapista: el esclavo-poeta no entendió, o no quiso entender, las limitaciones de su situación, convencido de que con sus dotes intelectuales y la manumisión sería realmente libre" ("Introducción" 22). Sin embargo, precisamente porque es consciente de su situación social Manzano puede anticiparse a su futuro, sabiendo que aunque lograra su libertad:

Se $q^{e}$. nunca $p^{r}$. mas $q^{e}$. me esfuerze con la verdad en los lavios ocupare el lugar de un hombre perfecto o de vien pero a lo menos ante el juisio sensato del hombre imparcial se berá hasta $\mathrm{q}^{\mathrm{e}}$. punto llega la preocupasion del mayor numero de los hombre contra el infeliz $\mathrm{q}^{\mathrm{e}}$. ha incurrido en alguna flaqueza (51).

La consciencia de Manzano de la contradicción en la que vive y escribe es ilustrativa de la del hombre de color que aspira al mundo letrado en una sociedad esclavista. Aunque la tensión causada por la aspiración a los valores del mundo blanco y los del mundo negro explique contradicciones lógicas en un régimen esclavista que va estructurando su sociedad basada en una pigmentocracia, no me parece que esta explicación sea suficiente en el caso de los intelectuales de color. El caso de Manzano representa la situación del intelectual de color que se siente "mulato" en cuanto a ser "fronterizo", no sólo racial sino intelectualmente, pues

\footnotetext{
${ }^{16}$ Véase la nota anónima que aparece al principio del manuscrito original, (Franco 33) y Schulman "Introducción" 49.
} 
aunque pertenezca al mundo libre de los de color, su condición de "hombre de letras" lo margina: "me consuelo cuando considero $\mathrm{q}^{\mathrm{e}}$. Dios me ha dado las desgracias, y también una alma $q^{e}$. me ase superior a algunos $\mathrm{q}^{e}$. sin el menor cuidado se rien de mi" (16 oct., 1834, Franco 79 , énfasis mío). Manzano nos dice que es socialmente inferior por su raza y superior por su saber. Es precisamente esta ambigüedad la que para mí explica que su saber se convierta en algo potencialmente peligroso para los blancos, tanto criollos como peninsulares.

Varios estudios han atribuido, con razón, al período de represión y racismo a raíz de los sucesos de la conspiración de La Escalera (1844), la causa del silencio de Manzano (Friol 62, Vitier 18-23). Pero la lectura que propongo del trabajo de Manzano implica que esta importante razón está ligada a la visión que se tenía del poeta-esclavo y a su función en la sociedad. El círculo agrupado bajo los auspicios de del Monte tenía definida la participación de Manzano en dicho proyecto. La importancia de Manzano para los intelectuales radicaba en ser un esclavo-poeta, que podía ofrecer un testimonio original que justificara sus razones para luchar contra el aumento de esclavos importados. Sin embargo, la incorporación del negro a la sociedad cubana, al proyecto de la fundación de la identidad y discurso nacional no entraba en los planes de la sacarocracia liberal; de hecho, es para contribuir al blanqueamiento racial y cultural de la sociedad cubana que se le pide su testimonio. ${ }^{17}$ Al dejar de ser esclavo, Manzano perdió toda su originalidad e importancia. Es su calidad de esclavo lo que lo hacía susceptible de ser manipulado por los intelectuales cubanos. Al ser manumitido, Manzano continuó publicando, dentro de su peculiar circunstancia de ex-esclavo y cuando sus obligaciones familiares se lo permitían. Manzano insiste en sus cartas que su producción literaria está condicionada a la satisfacción de las necesidades básicas personales y familiares (Franco 79, 85 ), en esto no era diferente a cualquier otro intelectual fuera de la elite criolla. No obstante, su obra no se juzgó por su mérito literario, sino por el hecho de ser producida por un autodidacta de color, ex-esclavo, como lo demuestra el anuncio de la subscripción a Zafira (Friol 67-68) o el artículo de del Monte comparando a Manzano con el poeta Matancero, Gabriel de la Concepción Valdés, Plácido. La variedad de temas en la obra de Manzano revela que no sólo quería emanciparse a nivel social, sino también intelectualmente; quería romper con el tema de la esclavitud en su obra y fue en este intento en el que no encontró padrinos que lo manumitieran. Manzano perdió el encanto que tenía para los intelectuales con su libertad, volviendo a ser silenciado. El ser esclavo-poeta o negro-poeta constituyó un atractivo que terminó por convertirse en causa para su represión final durante el proceso de la Escalera (1844), según concluye su propio defensor: "donde para graduarle de sospechoso no se produce otra razon que el ser Manzano un sugeto cuya ilustracion le hace obtener un gran prestigio entre los de su clase. ¡Es en verdad para este feliz bien fatal el privilegio del talento!” (Friol 210).

Las penas que pagaron Manzano y otros personajes de color de la sociedad cubana, como Plácido revela el doble sistema de represión que demarcaba la producción artística de los intelectuales de color. El relativo éxito del blanqueamiento cultural en la sociedad cubana puede demostrarse - entre otros ejemplos - por el silenciamiento de los intelectuales de color que produjeron antes de la abolición de la esclavitud. El olvido en que han sido sumidos otros escritores de color evidencia la falta de reconocimiento de que fueron objeto en el quehacer

${ }^{17}$ Para una explicación del blanqueamiento racial como antecedente al sentimiento nacionalista, referimos al lector a los trabajos de Richard Jackson y Winthrop Wright, entre otros. 
político e intelectual del siglo XIX. ${ }^{18}$ El rescate de estas figuras contribuiría a la revisión de la definición decimonónica de la cubanía todavía vigente.

\section{OBRAS CITADAS}

Bueno, Salvador. El negroen la novela hispanoamericana. LaHabana: Letras cubanas, 1986. Calcagno, Francisco. Poetas de color. Habana: Imprenta Mercantil, de los herederos de Santiago S. Spencer, 1887.

Centón epistolario de Domingo del Monte. 7 vols. Prefacio, anotaciones y una tabla alfabética Domingo Figarola Caneda. Habana: Imprenta El siglo XX, 1927.

DeCosta-Willis, Miriam. "Self and Society in the Afro-Cuban Slave Narrative". Latin American Literary Review 16.32 (julio-diciembre 1988): 6-15.

del Monte, Domingo. "Dos poetas negros: Plácido y Manzano". Humanismo y Humanitarismo. La Habana: Lex, 1960. 113-116.

Deschamps Chapeaux, Pedro. "Martí y la sociedad protectora de la instrucción de la Liga". Anuario Martiano 5 (1974): 61-71.

Doyle, Mary Ellen, S.C.N. "The Slavery as Rhetorical Art". The Art of Slave Narrative. Ed. John Sekora and Darwin T. Turner. Western Illinois University, An Essays in Literature Book, 1982. 83-95.

Edreira de Caballero, Angelina. Antonio Medina, el don Pepe de la raza de color. La Habana: Imprenta Molina y Cía., 1938.

Franco, José Luciano, ed. Autobiografia, cartas y versos. La Habana: Municipio de La Habana, 1937.

Friol, Roberto. Suite para Juan Francisco Manzano. La Habana: Arte y literatura, 1977. Ginzburg, Carlo. Elquesoylos gusanos. Trad. Francisco Martín. Barcelona: Muchnik, 1986. Gómez, Juan Gualberto. “Autobiografia”. Fondo Donativos Juan Gualberto Gómez, Legajo 144, no. 61, Archivo histórico nacional, La Habana.

González del Valle, JoséZ. La vida literaria en Cuba(1836-1840). LaHabana: Publicaciones de la Secretaría de Educacación de Cultura, 1938.

Jackson, Richard L. "Slavery, Racism and Autobiography in Two Early Black Writers: Juan Francisco Manzano and Martín Morúa Delgado". Voices from Under. Ed. William Luis. Westport: Greenwood, 1984. 55-64.

The Black Image in Latin American Literature. Albuquerque: University of New Mexico Press, 1976.

${ }^{18}$ La vida cultural de la población de color durante la esclavitud fue bastante activa y articulada. Ambrosio Echemendia, José del Carmen Díaz, Manuel Roblejo y Juan Antonio Frías son algunos de los poetas que produjeron durante su esclavitud. Díaz, después de haber sido manumitido, contribuyó junto con Rafael Serra a la fundación de la "Sociedad de Instrucción y Recreo La armonía" (Deschamp Chapeaux 61). Roblejo y Frías, participaron en la Guerra de los Diez años. Roblejo murió en el campo de batalla y Frías fue fusilado por el gobiemo español (Trelles, Bibliografia, IV: 298, 306). Antonio Medina, poeta, educador y fundador de la primera revista literaria de autores de color, estuvo relacionado a Plácido y Manzano (Calcagno 52, Edreira 7). Y a su vez, Juan Gualberto Gómez se educó y fue influenciado por Medina (Gómez 1). Tenemos un proyecto en preparación sobre este aspecto de la vida cultural cubana. 
Kutzinski, VeraM. Sugar's Secrets. Race and the Erotics ofCubanNationalism. Charlottesville: University Press of Virginia, 1993.

Luis, William. "Autobiografía del esclavo Juan Francisco Manzano: Versión de Suárez y Romero". La historia de la literatura iberoamericana. Ed. Raquel Chang-Rodríguez. Hanover: Ediciones del Norte, 1989. 25-268.

Literary Bondage, Slavery in Cuban Narrative. Austin: University of Texas Press, 1990.

Manzano, Juan Francisco. [Autobiografia, cartas y poemas]. Colección Cubana, Biblioteca Nacional José Martí, 1835.

Autobiografia y cartas del poeta Juan Francisco Manzano, chino esclavo de la Isla de Cuba. Colección Cubana, Biblioteca Nacional José Martí, 1859.

Obras completas de Juan Francisco Manzano, esclavo de la Isla de Cuba. Latin American Collection, Yale Library, 1852.

McDowell, Deborah Eland and Arnold Rampersad. Slavery and the Literary Imagination. Baltimore: John Hopkins University Press, 1989.

Molloy, Sylvia. "From Serf to Self: The Autobiography of Juan Francisco Manzano". Modern Language Notes 104.2 (1989): 393-417.

Netchinsky, Jill Ann. "Engendering a Cuban Literature: Nineteenth-Century Antislavery Narrative. (Manzano, Suárez y Romero, Gómez de Avellaneda, Antonio Zambrana)”. Dissertation Yale University, 1986.

Olney, James. "II Was Born': Slave Narratives, Their Status as Autobiography and as Literature". The Slave's Narrative. Ed. Charles T. Davis and Henry Louis Gates, Jr. Oxford: Oxford University Press, 1985. 148-175.

"The Founding Fathers-Frederick Douglass and Booker T. Washington". Slavery and the Literary Imagination. Ed. Deborah E. McDowell and Arnold Rampersad. Baltimore: John Hopkins University Press, 1989. 1-24.

Patterson, Orlando. Slavery and Social Death: A Comparative Study. Cambridge MA: Harvard University Press, 1982.

Ramos, Julio. "Cuerpo, lengua, subjetividad". Revista de Crítica Literaria Latinoamericana. 38 (1993): 225-237.

Schulman, Ivan A. "Introducción". Juan Francisco Manzano: Autobiografia de un esclavo. Madrid: Guadarrama, 1975. 9-54.

Trelles, Carlos M. "Bibliografia de autores de la raza de color". Cuba contemporánea 43 (1927): 30-78.

Vera Ledn, Antonio. "Juan Francisco Manzano: el estilo bárbaro de la nación". Hispamérica 20.60 (diciembre 1991): 3-22.

Vitier, Cintio. "Dos poetas cubanos: Plácido y Manzano". Bohemia 65.50 (1973): 20-22.

Wright, Winthrop R. Café con leche. Race, Class, and National Image in Venezuela. Austin: University of Texas Press, 1990. 
